\title{
Improved production of dibenzocyclooctadiene lignans in the elicited microshoot cultures of Schisandra chinensis (Chinese magnolia vine)
}

\author{
Agnieszka Szopa $^{1}$ D $\cdot$ Adam Kokotkiewicz $^{2} \cdot$ Agata Król $^{2} \cdot$ Maria Luczkiewicz $^{2}$ • \\ Halina Ekiert ${ }^{1}$
}

Received: 21 August 2017 / Revised: 4 November 2017 / Accepted: 7 November 2017 / Published online: 27 November 2017

(C) The Author(s) 2017. This article is an open access publication

\begin{abstract}
Dibenzocyclooctadiene lignans are a specific group of secondary metabolites that occur solely in Schisandra chinensis. The aim of the presented work was to boost the accumulation of lignans in the agitated microshoot cultures of $S$. chinensis, using different elicitation schemes. The experiments included testing of various concentrations and supplementation times of cadmium chloride $\left(\mathrm{CdCl}_{2}\right)$, chitosan $(\mathrm{Ch})$, yeast extract (YeE), methyl jasmonate (MeJa), and permeabilizing agent - dimethylsulfoxide (DMSO). After 30 days, the microshoots were harvested and evaluated for growth parameters and lignan content by LC-DAD method. The analyses showed enhanced production of lignans in the elicited $S$. chinensis microshoots, whereas the respective media samples contained only trace amounts of the examined compounds $(<5 \mathrm{mg} / \mathrm{l})$. Elicitation with $\mathrm{CdCl}_{2}$ caused up to 2-fold increase in the total lignan content (max. ca. $730 \mathrm{mg} / 100 \mathrm{~g} \mathrm{DW}$ after the addition of $1000 \mu \mathrm{M} \mathrm{CdCl}_{2}$ on the tenth day). Experiments with chitosan resulted in up to 1.35 -fold increase in lignan concentration (max. ca. $500 \mathrm{mg} / 100 \mathrm{~g} \mathrm{DW}$ ) after the supplementation with $50 \mathrm{mg} / \mathrm{l}$ on the first day and $200 \mathrm{mg} / \mathrm{l}$ on the tenth day. High improvement of lignan production was also recorded after YeE elicitation. After the elicitation with $5000 \mathrm{mg} / \mathrm{l}$ of YeE on the first day of the growth period, and with $1000 \mathrm{and} 3000 \mathrm{mg} / \mathrm{lon}$ the 20th day, the lignan production increased to the same degree - about 1.8-fold. The supplementation with $1000 \mathrm{mg} / \mathrm{YeE}$ on the 20th day of the growth cycle was chosen as the optimal elicitation scheme, for the microshoot cultures maintained in Plantform temporary immersion system - the total content of the estimated lignans was equal to $831.6 \mathrm{mg} / 100 \mathrm{~g} \mathrm{DW}$.
\end{abstract}

Keywords Elicitation $\cdot$ Temporary-immersion bioreactor $\cdot$ Schisandra lignan production $\cdot$ Biotic elicitors $\cdot$ Abiotic elicitors $\cdot$ In vitro cultures

\section{Introduction}

Schisandra chinensis (Turcz.) Baill., Chinese magnolia vine (Schisandraceae), is a climbing plant, naturally occurring in the countries of Eastern Asia, whereas in European countries, it grows mainly as an ornamental shrub (Panossian and Wikman 2008; Szopa et al. 2016a; Szopa et al. 2017a). The raw material of Schisandra fruits, Schisandrae chinensis fructus (chin. běi wǔ

Electronic supplementary material The online version of this article (https://doi.org/10.1007/s00253-017-8640-7) contains supplementary material, which is available to authorized users.

Agnieszka Szopa a.szopa@uj.edu.pl

1 Department of Pharmaceutical Botany, Jagiellonian University, Collegium Medicum, ul. Medyczna 9, 30-688 Kraków, Poland

2 Department of Pharmacognosy, Faculty of Pharmacy, Medical University of Gdańsk, al. gen. J. Hallera 107, 80-416 Gdańsk, Poland wèi zi; literally "five-flavor berry"), has been used for therapeutic purposes in traditional Chinese medicine and has successfully been included in pharmacopoeial monographs of Asian and European countries as well as in the USA Pharmacopoeia and the International Pharmacopoeia, printed by WHO (World Health Organization 2007; European Directorate for the Quality of Medicines. 2017; Szopa et al. 2017a). Numerous therapeutic properties of Schisandra fruit extracts, as well as its individual compounds, have been confirmed by the scientific research, carried out with the use of in vivo and in vitro models. The studies indicate that $S$. chinensis has a positive effect on liver functioning and stimulates cardiovascular, respiratory, and central nervous systems. The therapeutic properties of Chinese magnolia vine include anticancer, immunostimulant, and adaptogenic (Mocan et al. 2016; Szopa et al. 2016a; Szopa et al. 2017a). These activities are related to the presence of the dibenzocyclooctadiene lignans, known as "Schisandra lignans" (Figure S1), due to the fact that their occurrence is limited to S. chinensis (Fuss 2004; Opletal et al. 2004; Lu and Chen 2009). 
The dominant lignans that can be distinguished out of over 40 present in S. chinensis are as follows: schisandrin; gomisins A, C, F and N; deoxyschisandrin; and $\gamma$-schisandrin. The extracts of $S$. chinensis fruit have been used for the manufacture of medical products, food supplements, or cosmetics (Szopa et al. 2016a). Given the fact that the lignans of $S$. chinensis are therapeutically unique compounds, the research on alternative methods of their natural resource-independent acquisition has been performed. The methods of the chemical synthesis of Schisandra lignans have been developed; however, these had limited success due to their complex stereochemistry (Shi et al. 2009). The other alternative is plant cell culture which has so far been employed for the production of several biologically active secondary metabolites, including lignans. Moreover, it has been reported that in vitro techniques enable to enhance the production of lignans by means of elicitation, addition of biosynthetic precursors, and immobilization (Angelova et al. 2006; Verpoorte et al. 2002; Capote 2012; Ramirez-Estrada et al. 2016). Nevertheless, it should be noted that the so far conducted studies focused on the production of aryltetralin lignans in the in vitro cultures of various species of Podophyllum sp. and Linum sp. (Petersen and Alfermann 2001; Arroo et al. 2002; Koulman et al. 2003; Malik et al. 2014). On the other hand, there are only few studies dealing with the accumulation of Schisandra lignans under cell culture conditions (Fuss 2004). In our previous studies, agar, stationary liquid, and agitated microshoot cultures of S. chinensis were demonstrated to produce substantial amounts of dibenzocyclooctadiene lignans (Szopa et al. 2016b). Moreover, in our latest work, we optimized the production process of these compounds in different types of laboratory scale bioreactors (Szopa et al. 2017b).

The current work was aimed at determining the effect of elicitation on the accumulation of dibenzocyclooctadiene lignans in S. chinensis microshoots. The agitated cultures were supplemented with abiotic elicitor: cadmium chloride $\left(\mathrm{CdCl}_{2}\right)$, and biotic elicitors: chitosan $(\mathrm{Ch})$, yeast extract (YeE), methyl jasmonate (MeJa), and the permeabilizing agent - dimethylsulfoxide (DMSO). The elicitor-treated cultures were evaluated for growth (fresh weight [FW], dry weight [DW], growth index [Gi]) and lignan accumulation. The experiments included different concentrations and application times of elicitors. The most effective elicitation scheme was subsequently applied to bioreactor-grown microshoots.

\section{Materials and methods}

\section{Basic agar culture}

The microshoot cultures of Schisandra chinensis (Turcz.) Baill. (Szopa et al. 2016b), grown on agar Murashige and Skoog (MS) medium (Murashige and Skoog 1962) and supplemented with $30 \mathrm{~g} / 1$ sucrose, $3.0 \mathrm{mg} / 1 \mathrm{BA}$, and $1.0 \mathrm{mg} /$ $1 \mathrm{NAA}$ (further referred to as $\mathrm{MS}_{\mathrm{Sch}}$ medium), were used for the experiments. The cultures are deposited in the Department of Pharmaceutical Botany, Jagiellonian University, Poland. The cultures were maintained at $25 \pm 2{ }^{\circ} \mathrm{C}$ under constant light (white fluorescent tubes, $36 \mathrm{~W}, 88 \pm 8 \mu \mathrm{mol} \mathrm{m}{ }^{-2} \mathrm{~s}^{-1}$, Philips, Amsterdam, Netherlands) and subcultured at 60-day intervals.

\section{Agitated cultures}

For the agitated culture initiation, $1.5 \mathrm{~g}$ S. chinensis microshoots (see the "Basic agar culture" section), grown on $\mathrm{MS}_{\mathrm{Sch}}$ medium for 60 days, were placed into $125 \mathrm{ml}$ Erlenmeyer flasks, filled with $50 \mathrm{ml}$ liquid $\mathrm{MS}_{\mathrm{Sch}}$ medium, and closed with silicone sponge stoppers (Carl-Roth, Karlsruhe, Germany). The cultures were maintained on the rotary shaker at $120 \mathrm{rpm}$ (INNOVA 2300, Eppendorf, Enfield, US-CT), under light and temperature conditions described beforehand (see the "Basic agar culture" section).

\section{Bioreactor cultures}

S. chinensis shoots were grown for 30 days in Plantform temporary immersion system (Plant Form AB, Lomma, Sweden), as previously described (Szopa et al. 2017b). The bioreactor was inoculated at 15/500 microshoots to medium ratio $(\mathrm{g} / \mathrm{ml})$. The immersion cycle was set to $5 \mathrm{~min}$ every $1.5 \mathrm{~h}$, at $1.0 \mathrm{vvm}$ aeration rate.

\section{In vitro culture reagents}

The culture media were prepared using Sigma-Aldrich (St. Louis, MO, USA) reagents and type I water (Elix/Synergy system, Merck-Millipore, Billerica, MA, USA). Stock aqueous solutions of cadmium chloride $\left(\mathrm{CdCl}_{2}\right)(100,10,1$, and $0.1 \mathrm{mM}$, reagent grade, $\mathrm{POCH}$, Gliwice, Poland) and yeast extract (YeE) (250, 150, 50, and $5 \mathrm{~g} / \mathrm{l}$, plant cell culture tested, Sigma-Aldrich) for elicitor treatments were steam sterilized $\left(120{ }^{\circ} \mathrm{C}, 20 \mathrm{~min}, 1 \mathrm{bar}\right)$ prior to use. The stock solution of deacetylated crab shell chitosan (Ch) (5.0 g/l, Sigma-Aldrich) was prepared by dissolving $0.5 \mathrm{~g}$ of chitosan in $20 \mathrm{ml}$ of hot aqueous solution $(5 \% \mathrm{w} / \mathrm{w})$ of hydrochloric acid ( $\mathrm{HCl}$; Merck, Darmstadt, Germany). The obtained solution was diluted to $50 \mathrm{ml}$ with water, its $\mathrm{pH}$ was adjusted to 5.8 , using $1 \mathrm{M}$ sodium hydroxide, and diluted with water to the final volume of $100 \mathrm{ml}$. Experimental stock solutions of chitosan $(2.5,1.25$, and $0.625 \mathrm{~g} / \mathrm{l}$ ) were prepared by diluting the $5.0 \mathrm{~g} / 1$ solution with neutralized hydrochloric acid solution $(20 \mathrm{ml}$ of $5 \% \mathrm{v} / \mathrm{w}$ aqueous hydrochloric acid diluted with water to $50 \mathrm{ml}$, adjusted to $\mathrm{pH} 5.8$, using $1 \mathrm{M}$ sodium hydroxide, and diluted to the final volume of $100 \mathrm{ml}$ ). The stock solutions of chitosan as well as neutralized $\mathrm{HCl}$ solution (used for the control 
experiments in the elicitor treatments) were steam sterilized $\left(120{ }^{\circ} \mathrm{C}, 20 \mathrm{~min}, 1 \mathrm{bar}\right)$ prior to use.

\section{Elicitor treatments}

\section{Elicitation of the agitated microshoot cultures}

Sterile stock solutions of elicitors (prepared as described in the "In vitro culture reagents" section) were added to the agitated microshoot cultures (established as described in the "Agitated cultures" section) on the first, 10th, and 20th day of the 30-day growth period. The stock solutions of cadmium chloride $\left(\mathrm{CdCl}_{2}\right)$, yeast extract $(\mathrm{YeE})$, and chitosan $(\mathrm{Ch})$ were added at $0.5,1.0$, and $2.0 \mathrm{ml}$ per flask, respectively, yielding the final concentrations of $1000,100,10$, and $1 \mu \mathrm{M}\left(\mathrm{CdCl}_{2}\right) ; 5000$, 3000,1000 , and $100 \mathrm{~g} / 1$ (YeE); and 200, 100, 50, and $25 \mathrm{mg} / \mathrm{l}(\mathrm{Ch})$ in the growth medium. The control groups constituted the agitated microshoots without elicitor treatment (all experiments), as well as the cultures supplemented with neutralized $\mathrm{HCl}$ solution (see the "In vitro culture reagents" section; chitosan experiments only). After 30 days, the microshoots and media samples were collected, freeze-dried (LYOVAC GT2 apparatus, Finn-Aqua Santasolo-Sohlberg, Tuusula, Finland), and subjected to phytochemical analysis.

\section{Elicitation of the bioreactor-grown microshoots cultures}

For the Plantform bioreactor experiments, the elicitation protocol with $1000 \mathrm{mg} / \mathrm{l}$ of YeE, supplemented on the 20th day of the growth period, was applied. For elicitation, one of the side hose nipples of Plantform bioreactor was used as an inlet port. The microshoots and media samples were collected on the 30th day of the experiment. The samples were freeze-dried and subjected to phytochemical analysis.

\section{Calculating the growth parameters}

The growth parameters were expressed as fresh and dry weight (FW and DW, determined before and after freeze-drying, respectively), as well as growth index (Gi), calculated according to the formula: $\mathrm{Gi}=[(\mathrm{FW} 1-\mathrm{FW} 0) / \mathrm{FW} 1] \times 100$, where FW1 is the fresh weight of microshoots at the end of the experiment and FW0 is the fresh weight of the inoculum.

\section{Extraction, separation, and quantification of Schisandra lignans}

The lyophilized (LYOVAC GT2 apparatus, Finn-Aqua Santasolo-Sohlberg, Tuusula, Finland) biomass samples, collected after the 30 th day of the growth periods $(0.5 \mathrm{~g}$ of DW (dry weight)) from each of four experimental series, were sonicated (Polsonic 3, Warszawa, Poland) at a frequency of
$40 \mathrm{kHz}$ and an intensity of $160 \mathrm{~W}$, with methanol $(2 \times 50 \mathrm{ml})$ at $30^{\circ} \mathrm{C}$. The lyophilized media samples $(40 \mathrm{ml})$ were extracted in $5 \mathrm{ml}$ of methanol. For the estimation of lignan contents, quantification was carried out by liquid chromatography with diode array detection (LC-DAD), as described previously (Zhang et al. 2009; Szopa et al. 2016b; Szopa et al. 2017b).

\section{Statistical analysis}

The experiments have been repeated thrice. The results were presented as mean \pm standard deviation (SD). The STATISTICA version 12 PL software package (StatSoft) was used for the analysis. The results of total lignan contents were compared with the one-way analysis of variance (oneway ANOVA). For comparison and contrast between different groups, post hoc Tukey HSD (honestly significant difference) test was used.

\section{Results}

\section{Preliminary experiments}

In the course of preliminary experiments, the biomass was elicited with methyl jasmonate (MeJa) at 50, 100, and $200 \mu \mathrm{M}$ and cadmium chloride $\left(\mathrm{CdCl}_{2}\right)$ at $2.5,5,10$, and $20 \mathrm{mM}$. Additionally, dimethylsulfoxide (DMSO) at 0.2, 2, 4 , and $8 \% v / v$ was tested as a permeabilizing agent. All tested agents were added on the 23 th or the 27 th day, and the experiment was run for 30 days. The collected shoots were evaluated for growth and lignan content, and the results were included as supplementary Figures S2-S4 and Tables S1-S3 (Online resource 1). In all elicited biomass extracts, fourteen dibenzocyclooctadiene lignans were detected: schisandrin, gomisin A, gomisin G, schisantherin A, schisantherin B, schisanthenol, deoxyschisandrin, $\gamma$-schisandrin, schisandrin C, angeoyl/tigloylgomisin H, angeoyl/tigloylgomisin Q, schisandrin $\mathrm{B}$, benzoylgomisin $\mathrm{P}$, and schisantherin $\mathrm{D}$ (Tables S1-S3).

Medium supplementation with DMSO caused the decrease in intracellular lignan content. The greatest decrease of total lignan contents was observed for the addition of $40 \mathrm{ml} / 1$ of DMSO on 27th (239.9 mg/100 g DW) and 23rd (312.9 mg/ $100 \mathrm{~g} \mathrm{DW}$ ) days of culture growth. This relation was not accompanied by the increase of the lignan concentration in the growth medium (Table S1). The detected amounts in the media samples were low, below $5 \mathrm{mg} / \mathrm{l}$. The DMSO also restrains the biomass growth (Figure S2).

The experiments with MeJa showed variable influence of this elicitor on $S$. chinensis microshoot growth, the Gi factor oscillated between 254 and 346\% (Figure S3). Depending on concentration, MeJa either moderately decreased or did not affect the accumulation of lignans (max. total content 300- 
$400 \mathrm{mg} / 100 \mathrm{~g} \mathrm{DW}$ (Table S2). The highest contents, $427.8 \mathrm{mg} / 100 \mathrm{~g} \mathrm{DW}$, were detected after the addition of $50 \mu \mathrm{M}$ of MeJa on the 23rd day. As in the case of DMSO supplementation, the media samples showed trace presence of lignans.

Among the preliminary experiments, the best results were obtained by $\mathrm{CdCl}_{2}$ elicitation: its addition to the growth medium caused up to 2 -fold increase in lignan content $(597.3 \mathrm{mg} / 100 \mathrm{~g} \mathrm{DW}$ and $652.5 \mathrm{mg} / 100 \mathrm{~g} \mathrm{DW}$, after the addition of 2.5 or $20 \mathrm{mM} \mathrm{CdCl}_{2}$ on the 23 rd day, respectively) (Table S3). In the applied concentration range, $\mathrm{CdCl}_{2}$ was toxic for the shoots, as they showed visible signs of necrosis (darkening, medium browning). The growth rates, however, were not lower than in the control group (Figure S4). The supplementary experiment, involving the application of $\mathrm{CdCl}_{2}$ at $1.25-2500 \mu \mathrm{M}$ on the first day of the growth cycle demonstrated that growth inhibition occurs at $\geq 125 \mu \mathrm{M}$ $\mathrm{CdCl}_{2}$ (Figure S5). Low concentrations of cadmium ions $(1.25 \mu \mathrm{M})$, on the other hand, did not negatively affect culture growth while exerting moderately stimulating effect on lignan accumulation (Table S4). The highest total lignan content was obtained after the addition of $2500 \mu \mathrm{M}$ of MeJa. The respective media samples collected after elicitations with $\mathrm{CdCl}_{2}$ showed only trace amounts of the examined compounds $(<5 \mathrm{mg} / \mathrm{l})$.

\section{The influence of elicitation on microshoots' growth and morphology}

In the applied concentration range (see the "Elicitor treatments" section), the elicitors did not change microshoots' morphology. However, the shoots elicited with the highest doses of the elicitors were brownish and darkish, compared to the control group.

Elicitation with the lower concentrations, 1 and $10 \mu \mathrm{M}$ of $\mathrm{CdCl}_{2}$, had a positive effect on the biomass growth, irrespective of the time of elicitation. The calculated Gi factors ranged from 493.4 to $556.7 \%$, in comparison with $407.4 \%$ recorded for the control samples. The higher concentrations, 100 and $1000 \mu \mathrm{M}$ of $\mathrm{CdCl}_{2}$ supplemented on the first day of the growth period, noticeably decreased the growth increments. The Gi factor for the biomass elicited with $1000 \mu \mathrm{M} \mathrm{CdCl}_{2}$ on the 20th day was about four times lower than in the control samples (Fig. 1).

The YeE added at $100 \mathrm{mg} / \mathrm{l}$ slightly influenced the biomass growth, with the Gi index (333.7-428.9\%) comparable to the control samples (407.4\%). All other YeE concentrations tested remarkably decreased the growth rates. The most noticeable decrease in Gi factor was observed after the addition of 3000 and $5000 \mathrm{mg} / \mathrm{l} \mathrm{YeE}$ on the first day of the growth period (Fig. 2).

The elicitation with chitosan, in the applied concentration range $(25-200 \mathrm{mg} / \mathrm{l})$, did not negatively affect the microshoot growth. Regardless of the supplementation time, the growth indices of the chitosan-supplemented shoots were similar (or higher) to those of the control samples. The highest Gi value was noted for supplementation with 50 and $100 \mathrm{mg} / \mathrm{l} \mathrm{Ch}$ on the first day of the experiment (573.9 and $568.7 \%$ respectively, Fig. 3).

\section{The effect of elicitation on the accumulation of lignans in the agitated microshoot cultures}

The amounts of the main Schisandra lignans were estimated by chromatographic method in the methanolic extracts from the elicited microshoots, collected after 30-day growth periods. During the individual experiments, four dilutions of each elicitor were added, successively, on the first, 10th, and 20th days of the growth period. The elicitors and their concentrations were selected basing on the preliminary experiments, described in the supplementary data and above. In all samples irrespectively of the applied elicitation strategy, 14 dibenzocyclooctadiene lignans were estimated: schisandrin, gomisin A, gomisin G, schisantherin A, schisantherin B, schisanthenol, deoxyschisandrin, $\gamma$-schisandrin, schisandrin C, angeoyl/tigloylgomisin H, angeoyl/tigloylgomisin Q, schisandrin $\mathrm{B}$, benzoylgomisin $\mathrm{P}$, and schisantherin $\mathrm{D}$ (Tables 1, 2, 3, and 4). In the all analyzed samples, the main compounds were schisandrin, gomisin A, deoxyschisandrin, angeloyl/tigloylgomisins $\mathrm{Q}$ and $\mathrm{H}$, and benzoylgomisin $\mathrm{P}$. In the all experimental media samples, only the traces of the studied lignans were detected.

Cadmium ions proved to be the most effective at $1000 \mu \mathrm{M}$ when applied on the first, 10th, or 20th day of the experiment, with the total contents of Schisandra lignans equal to 522.9, 730.6 , and $585.5 \mathrm{mg} / 100 \mathrm{~g} \mathrm{DW}$, respectively (Table 1). Correspondingly, these amounts were 1.4, 2.0, and 1.6 times higher than in the control samples. The contents of the main Schisandra lignans, schisandrin and gomisin A, in the extracts from the biomass collected after the elicitation with $1000 \mu \mathrm{M}$ on the tenth day, were equal to $183.6 \mathrm{mg} / 100 \mathrm{~g}$ DW and $115.9 \mathrm{mg} / 100 \mathrm{~g}$ DW and were up to 2.4 and 2 times higher than in the control samples, respectively. The rest of the lower concentrations of $\mathrm{CdCl}_{2}$ added on the first, 10th and 20th days of microshoot growth periods slightly influenced on the lignan production.

The experiments involving biotic elicitor, YeE, supplemented in concentrations: $100,1000,3000$, and $5000 \mathrm{mg} / \mathrm{l}$ on the first, 10th, or 20th day of the experiment, as shown in Table 2, caused up to 1.85-time increase in the total production of Schisandra lignans, in the agitated microshoots. The highest total amounts of lignans were estimated in the extracts from microshoots, elicited with $3000 \mathrm{mg} / \mathrm{l}$ of $\mathrm{YeE}$ $(660.2 \mathrm{mg} / 100 \mathrm{~g} \mathrm{DW})$ and $5000 \mathrm{mg} / \mathrm{l}$ of YeE $(679.3 \mathrm{mg} /$ $100 \mathrm{~g} \mathrm{DW})$ on the first day, $5000 \mathrm{mg} / 1(572.7 \mathrm{mg} / 100 \mathrm{~g}$ DW) on the tenth day, and $1000 \mathrm{mg} / 1(639.9 \mathrm{mg} / 100 \mathrm{~g}$ 
Fig. 1 The effect of cadmium chloride on biomass growth in agitated shoot cultures of

$S$. chinensis. a Fresh weight (FW). b Dry weight (DW). c Growth index (Gi). Symbols used: $\mathrm{C}$ - control group without cadmium chloride treatment. The cultures were grown for 30 days
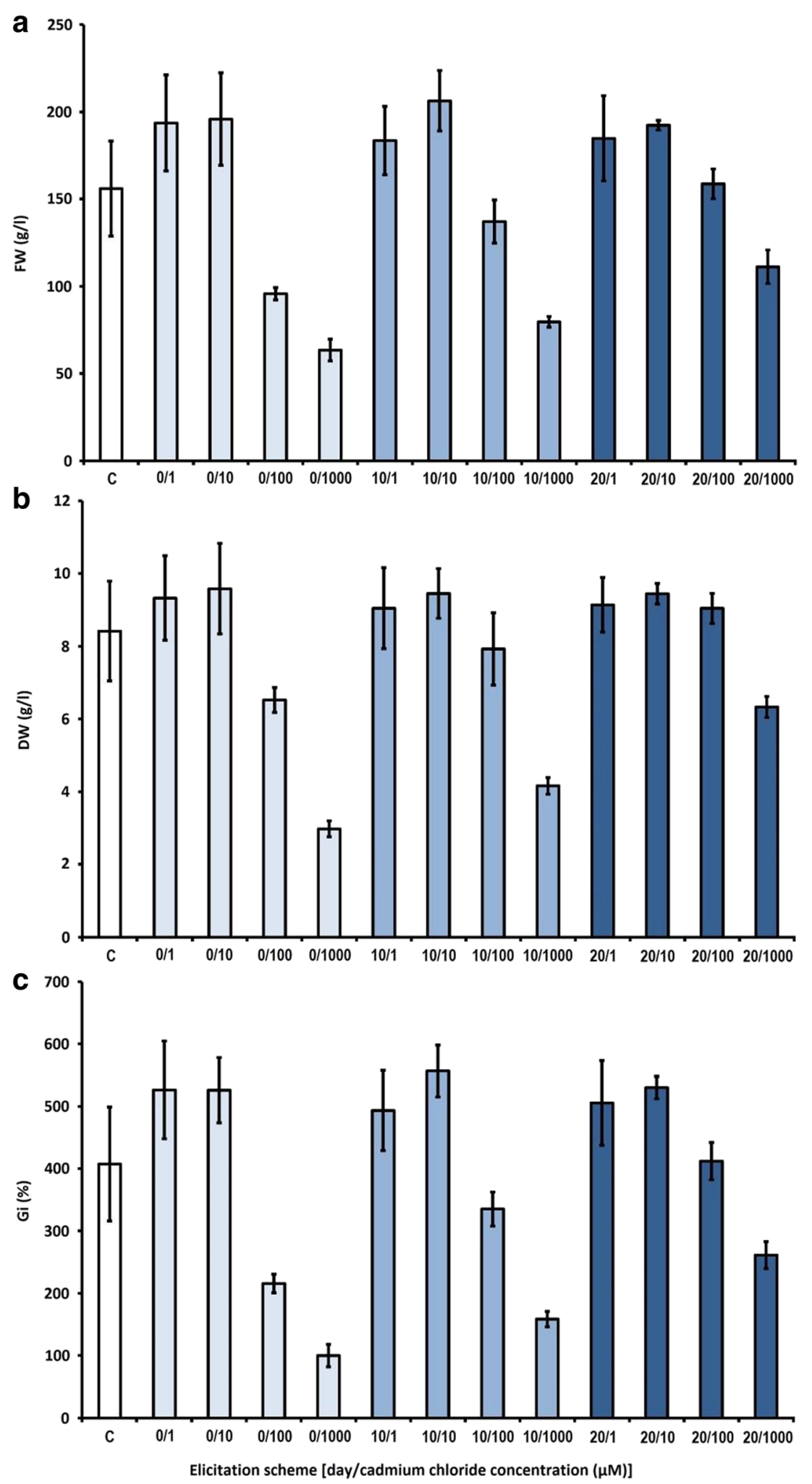

DW), $3000 \mathrm{mg} / 1(655.6 \mathrm{mg} / 100 \mathrm{~g} \mathrm{DW})$, and $5000 \mathrm{mg} / 1$ $(596.3 \mathrm{mg} / 100 \mathrm{~g} \mathrm{DW})$ on the 20th day of the experiment. The highest amounts of the main, individual compounds were confirmed as follows: schisandrin $-175.2 \mathrm{mg} / 100 \mathrm{~g}$ DW $(5000 \mathrm{mg} / \mathrm{l} \mathrm{YeE}$ on the 1st day), and gomisin A-
$139.1 \mathrm{mg} / 100 \mathrm{~g} \mathrm{DW}(1000 \mathrm{mg} / \mathrm{l} \mathrm{YeE}$ on the 20th day of experiment). The most effective for the total and individual lignan production as well as the biomass increments was the elicitation scheme with $1000 \mathrm{mg} / \mathrm{l} \mathrm{YeE}$ on the 20th day of experiment (Fig. 2 and Table 2). 
Fig. 2 The effect of yeast extract on biomass growth in agitated shoot cultures of $S$. chinensis. a Fresh weight (FW). b Dry weight (DW). c Growth index (Gi).

Symbols used: $\mathrm{C}$ - control group without yeast extract treatment.

The cultures were grown for 30 days
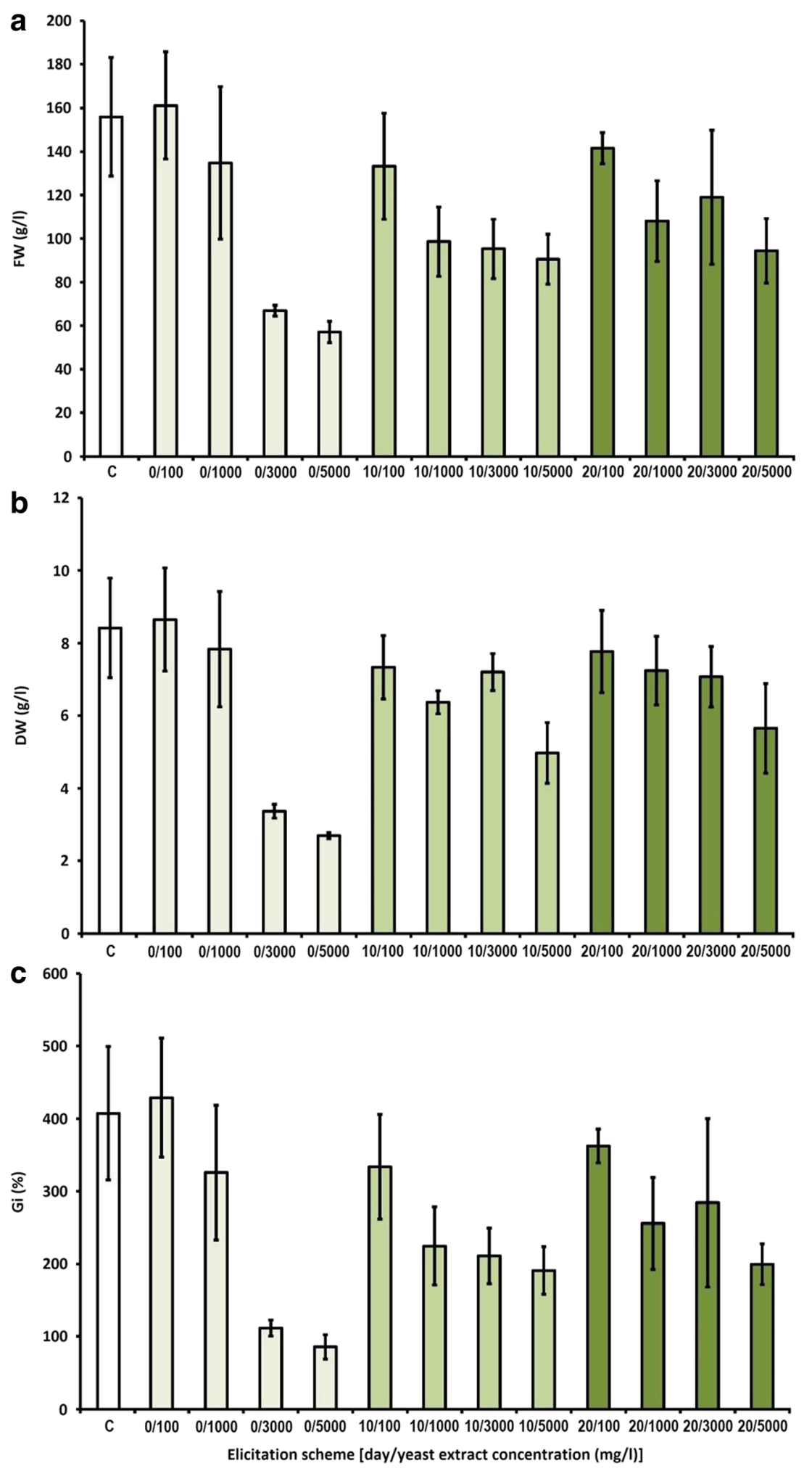

Elicitation with the second biotic elicitor, $\mathrm{Ch}$ (chitosan), in all the tested solutions on the 20th day of the growth period only marginally influenced the production of Schisandra lignans (Table 3). The most favorable results were obtained for the microshoots elicited on the first and the tenth day. In these samples, the total amounts of lignans were quite similar, ranging from $410.7 \mathrm{mg} / 100 \mathrm{~g} \mathrm{DW}(100 \mathrm{mg} / \mathrm{l} \mathrm{Ch}$ on the tenth day) to $508.1 \mathrm{mg} / 100 \mathrm{~g} \mathrm{DW}(50 \mathrm{mg} / \mathrm{l} \mathrm{Ch}$ on the first day). The maximal total content of lignans was ca. 1.3 times higher than in the control sample. The maximal contents of main 
Fig. 3 The effect of chitosan on biomass growth in agitated shoot cultures of $S$. chinensis. a Fresh weight (FW). b Dry weight (DW). c Growth index (Gi). Symbols used: $\mathrm{C}$ - control group without chitosan treatment, $\mathrm{S}$ control group without chitosan treatment, supplemented with neutralized hydrochloric acid solution. The cultures were grown for 30 days
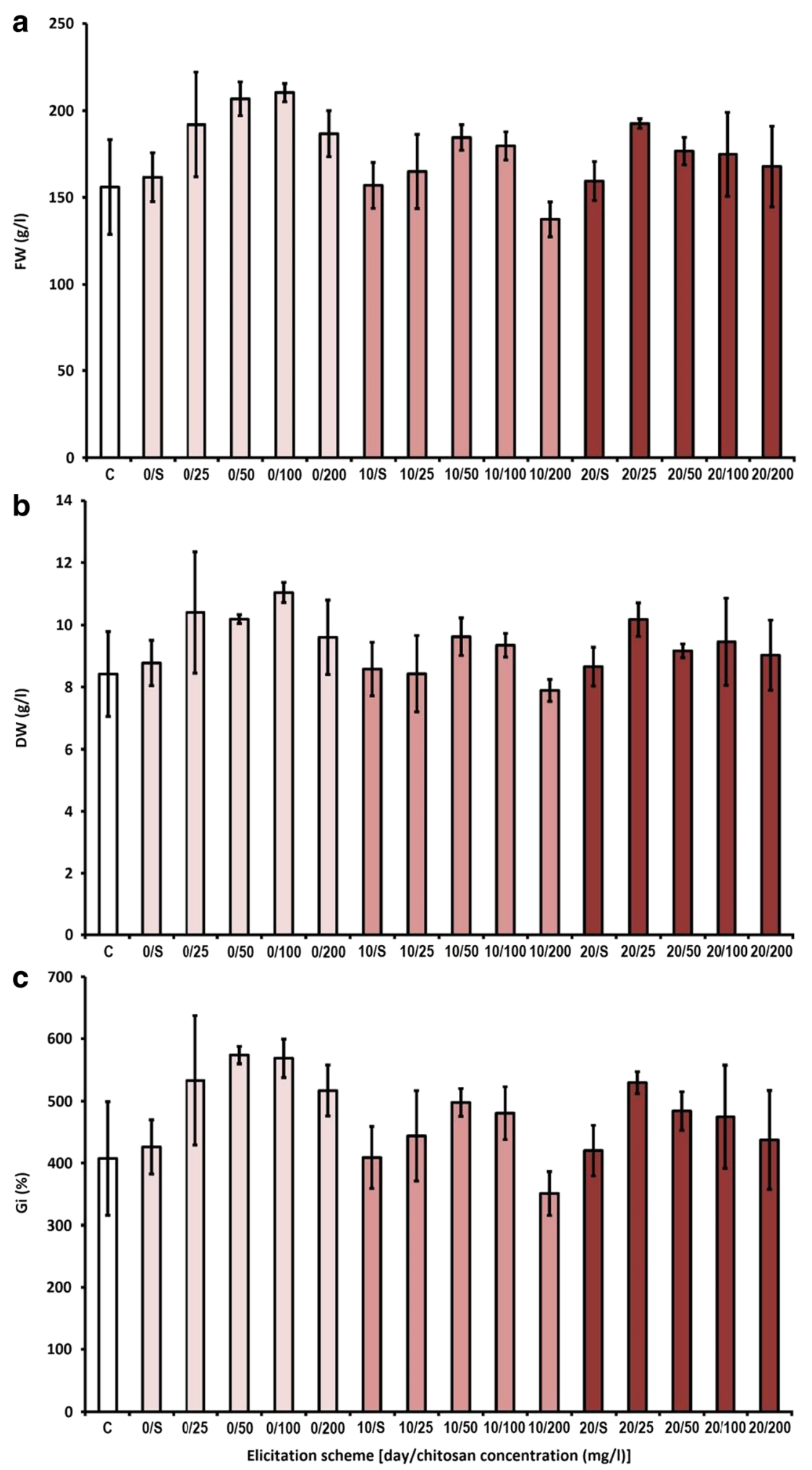

Schisandra lignans amounted ca. $115 \mathrm{mg} / 100 \mathrm{~g}$ DW for schisandrin, $52 \mathrm{mg} / 100 \mathrm{~g}$ DW for gomisin A, and $35 \mathrm{mg} /$ $100 \mathrm{~g}$ DW for deoxyschisandrin and were detected after elicitation with $50 \mathrm{mg} / \mathrm{l}$ on the first day and $200 \mathrm{mg} / \mathrm{l}$ on the tenth day of experiment.
Scaling up of the elicitation process in the temporary immersion bioreactors

For the bioreactor experiment was chosen the most effective elicitation protocol, selected by the review of experiments 


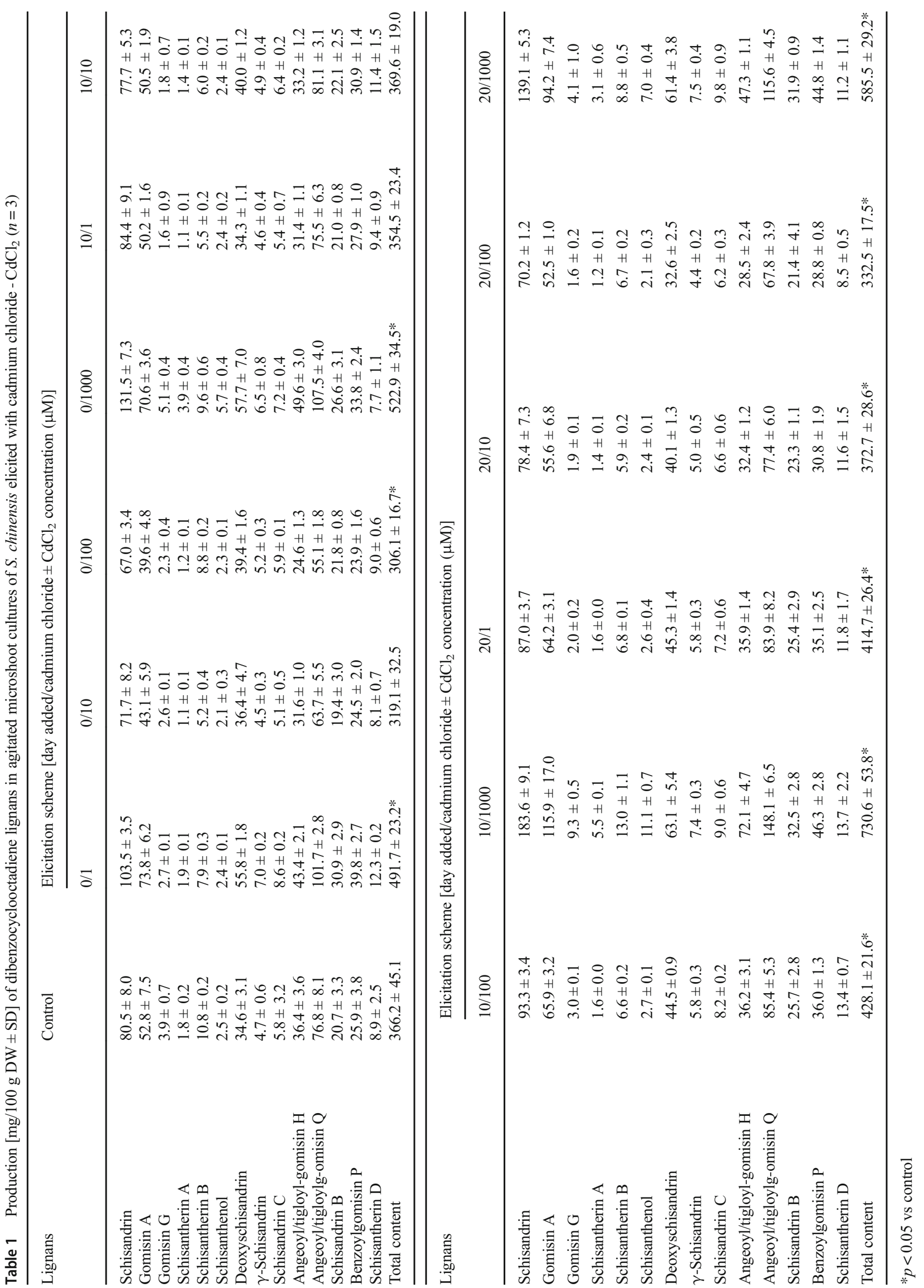




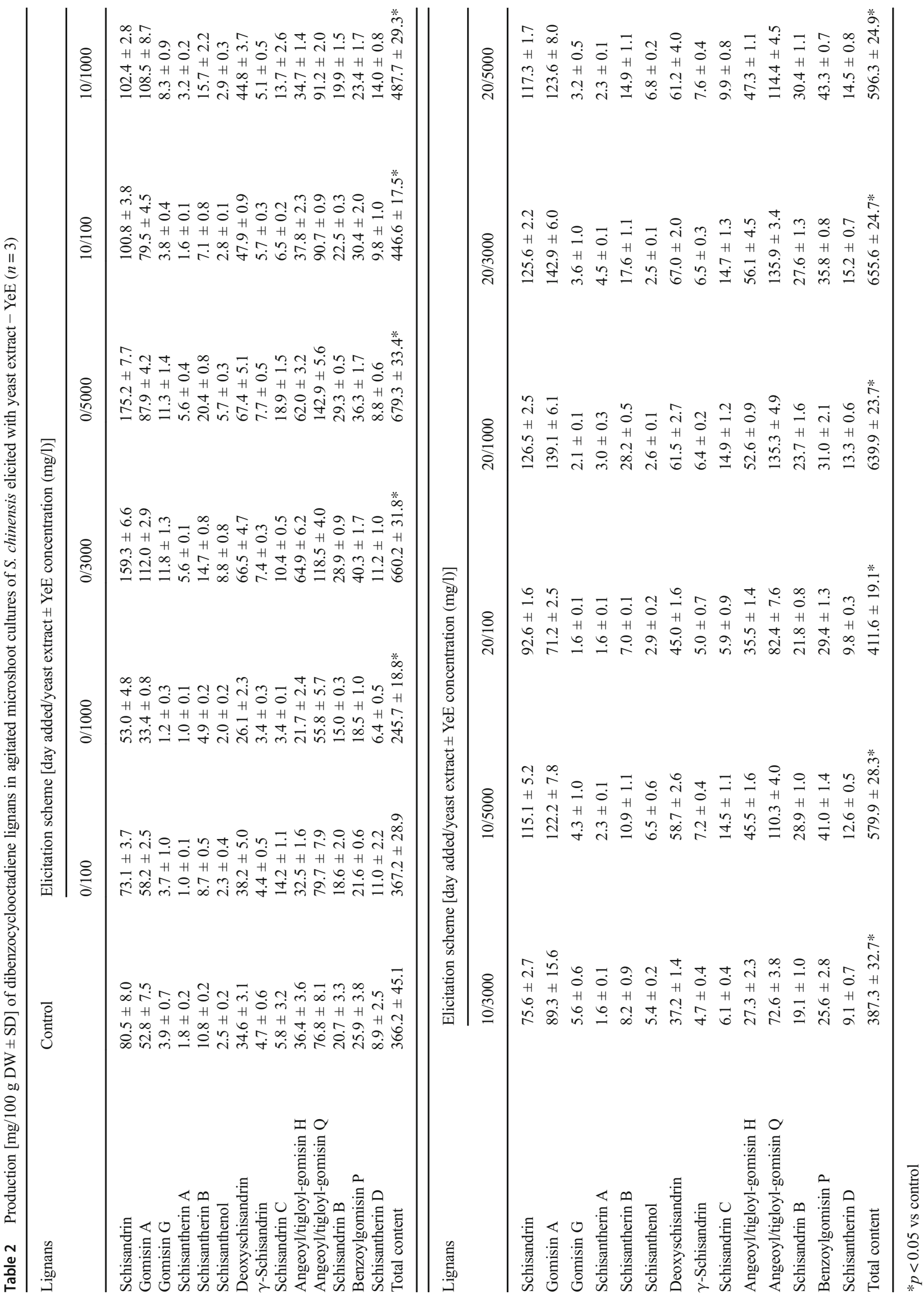




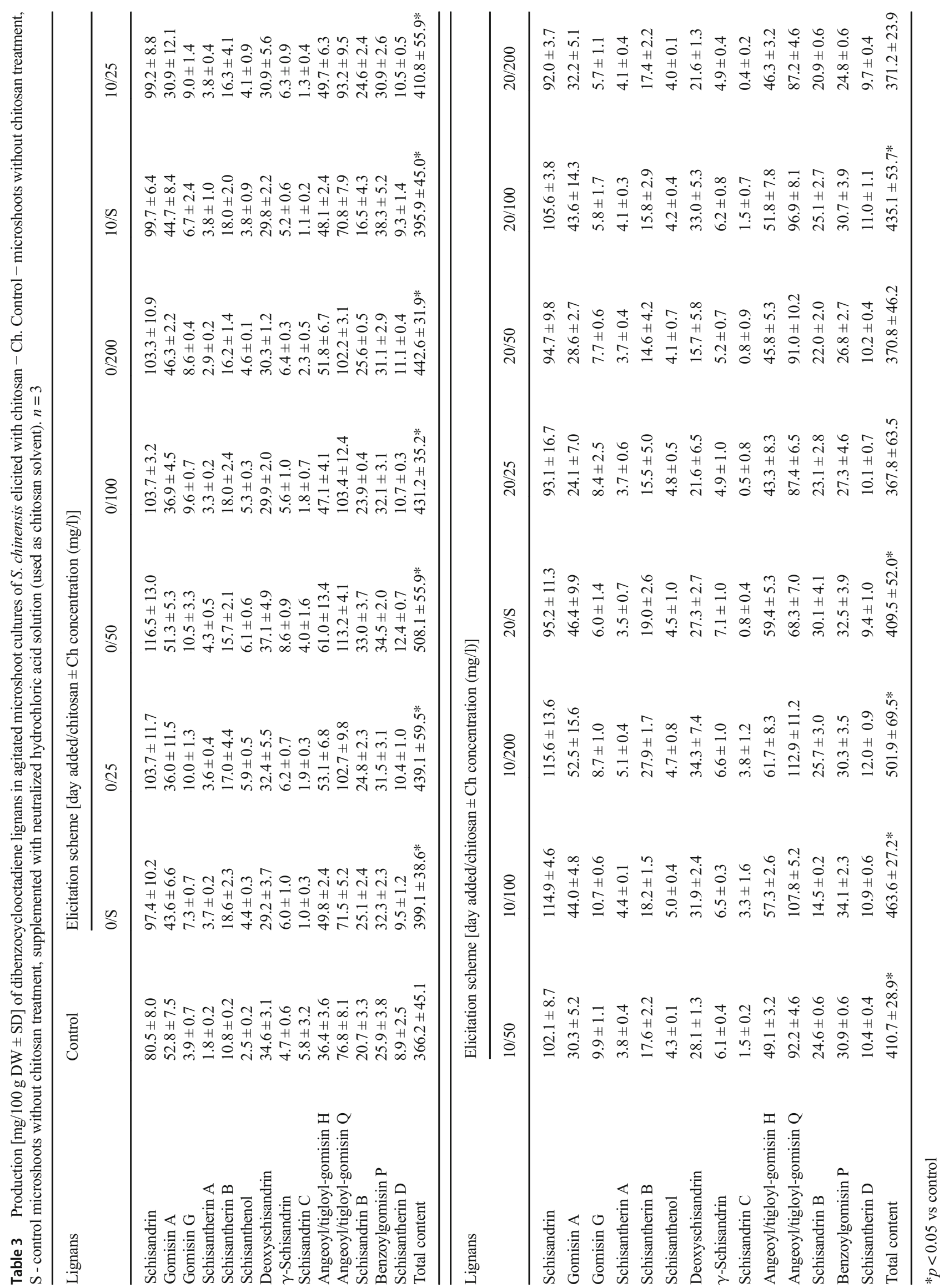


Table 4 Production $[\mathrm{mg} / 100 \mathrm{~g}$ $\mathrm{DW} \pm \mathrm{SD}]$ of

dibenzocyclooctadiene lignans in agitated microshoot cultures of $S$. chinensis and maintained in Plantform temporary immersion system elicited with $1000 \mathrm{mg} / \mathrm{l}$ of yeast extract (YeE) on the 20th day. $n=4$

\begin{tabular}{|c|c|c|c|c|}
\hline \multirow[t]{2}{*}{ Lignans } & \multicolumn{2}{|c|}{ Agitated microshoots } & \multicolumn{2}{|c|}{ Plantform bioreactor } \\
\hline & Control & YeE elicitation & Control & YeE elicitation \\
\hline Schisandrin & $80.5 \pm 8.0$ & $126.5 \pm 2.5$ & $128.7 \pm 17.8$ & $186.8 \pm 9.7$ \\
\hline Gomisin A & $52.8 \pm 7.5$ & $139.1 \pm 6.1$ & $55.4 \pm 17.6$ & $97.2 \pm 8.5$ \\
\hline Gomisin G & $3.9 \pm 0.7$ & $2.1 \pm 0.1$ & $6.1 \pm 0.8$ & $11.5 \pm 1.0$ \\
\hline Schisantherin A & $1.8 \pm 0.2$ & $3.0 \pm 0.3$ & $2.6 \pm 0.2$ & $4.8 \pm 0.3$ \\
\hline Schisantherin B & $10.8 \pm 0.2$ & $28.2 \pm 0.5$ & $14.6 \pm 2.1$ & $26.0 \pm 2.1$ \\
\hline Schisanthenol & $2.5 \pm 0.2$ & $2.6 \pm 0.1$ & $2.1 \pm 0.2$ & $3.7 \pm 0.2$ \\
\hline Deoxyschisandrin & $34.6 \pm 3.1$ & $61.5 \pm 2.7$ & $62.5 \pm 14.6$ & $100.0 \pm 8.2$ \\
\hline$\gamma$-Schisandrin & $4.7 \pm 0.6$ & $6.4 \pm 0.2$ & $7.2 \pm 0.3$ & $13.6 \pm 1.6$ \\
\hline Schisandrin C & $5.8 \pm 3.2$ & $14.9 \pm 1.2$ & $2.2 \pm 1.6$ & $8.3 \pm 0.6$ \\
\hline Angeoyl/tigloyl-gomisin $\mathrm{H}$ & $36.4 \pm 3.6$ & $52.6 \pm 0.9$ & $35.0 \pm 10.6$ & $85.2 \pm 5.5$ \\
\hline Angeoyl/tigloyl-gomisin Q & $76.8 \pm 8.1$ & $135.3 \pm 4.9$ & $104.4 \pm 3.4$ & $183.4 \pm 11.9$ \\
\hline Schisandrin B & $20.7 \pm 3.3$ & $23.7 \pm 1.6$ & $24.5 \pm 1.4$ & $41.8 \pm 2.3$ \\
\hline Benzoylgomisin P & $25.9 \pm 3.8$ & $31.0 \pm 2.1$ & $32.6 \pm 0.7$ & $56.5 \pm 3.4$ \\
\hline Schisantherin D & $8.9 \pm 2.5$ & $13.3 \pm 0.6$ & $11.0 \pm 0.5$ & $12.8 \pm 0.5$ \\
\hline Total content & $366.2 \pm 45.1$ & $639.9 \pm 23.8^{*}$ & $488.8 \pm 71.9$ & $831.6 \pm 55.8^{*}$ \\
\hline
\end{tabular}

$* p<0.05$ vs control conducted on the agitated cultures (Figs. 1, 2, and 3, Tables 1, 2, and 3). The employed elicitation scheme involved YeE, supplemented at $1000 \mathrm{mg} / \mathrm{l}$, on the 20th day of the growth period. The choice was based on the good growth parameters, high lignan content (Fig. 2, Table 2), and nontoxicity of YeE.

The growth parameters of the elicited microshoots grown in a bioreactor were not considerably changed in relation to the control experiments. In both cases, the Gi factor oscillated about $300 \%$ (Fig. 4). There were no differences in the morphology of the elicited and non-elicited shoots.

The total obtained amount $(831.6 \mathrm{mg} / 100 \mathrm{~g} \mathrm{DW})$ of Schisandra lignans in the elicited microshoots improved 1.7 times in comparison with the untreated biomass, maintained in bioreactor ( $488.8 \mathrm{mg} / 100 \mathrm{~g} \mathrm{DW}$ ) (Table 4). The total amounts of lignans in elicited bioreactor culture were the highest in the presented series of experiments. In the extracts from elicited microshoots cultured in Plantform bioreactor, high amounts of the main lignans: schisandrin $-186.8 \mathrm{mg} / 100 \mathrm{~g} \mathrm{DW}$, gomisin A $-97.2 \mathrm{mg} / 100 \mathrm{~g} \mathrm{DW}$, and deoxyschisandrin-100.0 mg/ $100 \mathrm{~g} \mathrm{DW}$, were estimated.

\section{Discussion}

The preliminary elicitation experiments were based on the results of the previous studies on lignan-producing plant in vitro cultures. These reports indicated that methyl jasmonate (MeJa), applied at 50-400 $\mu \mathrm{M}$ and not earlier than 9 days before the end of an experiment, noticeably increased the accumulation of aryltetralin lignans (Bahabadi et al. 2011; Bhattacharyya et al. 2012; Wawrosch et al. 2014). In the course of our experiments on $S$. chinensis microshoots, the biomass was elicited with MeJa at 50,100 , and $200 \mu \mathrm{M}$ on the $23 \mathrm{rd}$ and/or the 27 th day of the growth cycle and collected on the 30th day (Figure S3, Table S2). Moreover, the experiments included cadmium chloride $\left(\mathrm{CdCl}_{2}\right)$ (Figure S4, Table $\mathrm{S} 3$ ), which was previously shown to increase the accumulation of biologically active lignans (phyllanthin and hypophyllanthin) in Phyllanthus amarus (Rai et al. 2005), and dimethylsulfoxide (DMSO) (Figure S2, Table S1), demonstrated to act as both elicitor of secondary metabolism (Mannan et al. 2010) and an effective permeabilizing agent (Luczkiewicz and Kokotkiewicz 2012; Jaremicz et al. 2014). $\mathrm{CdCl}_{2}$ was applied at 2.5, 5, 10, and $20 \mathrm{mM}$, and DMSO was added at $0.2,2,4$, and $8 \% v / v$. As in the case of MeJa, both agents were added on the 23th or the 27th day and the experiment was run for 30 days.

Owing to the results of the preliminary studies, further elicitation experiments were designed. These were aimed at examining the influence of varying concentrations of the elicitors, added on different phases of the growth period (Figs. 1, 2, and 3 and Tables 1, 2, and 3), on shoot growth and lignan accumulation. The experiments included $\mathrm{CdCl}_{2}$ (the most effective elicitor in preliminary work), whereas MeJa and DMSO were excluded from the studies. Besides $\mathrm{CdCl}_{2}$, two biotic elicitors were used in the experiment: yeast extract (YeE) and chitosan (Ch). Based on the other studies, both YeE and Ch were demonstrated to stimulate aryltetralin lignan accumulation in plant cell and organ cultures (Esmaeilzadeh Bahabadi et al. 2014; Wawrosch et al. 2014; Malik et al. 2014).

The amounts of the main Schisandra lignans were estimated in the methanolic extracts from the elicited microshoots, collected after 30-day growth periods. In general, the 
Fig. 4 The effect of yeast extract (added at $1000 \mathrm{mg} / \mathrm{l}$ on day 20) on biomass growth in agitated and bioreactor-grown shoot cultures of $S$. chinensis. a Fresh weight (FW). b Dry weight (DW). c Growth index (Gi). The cultures were grown for 30 days
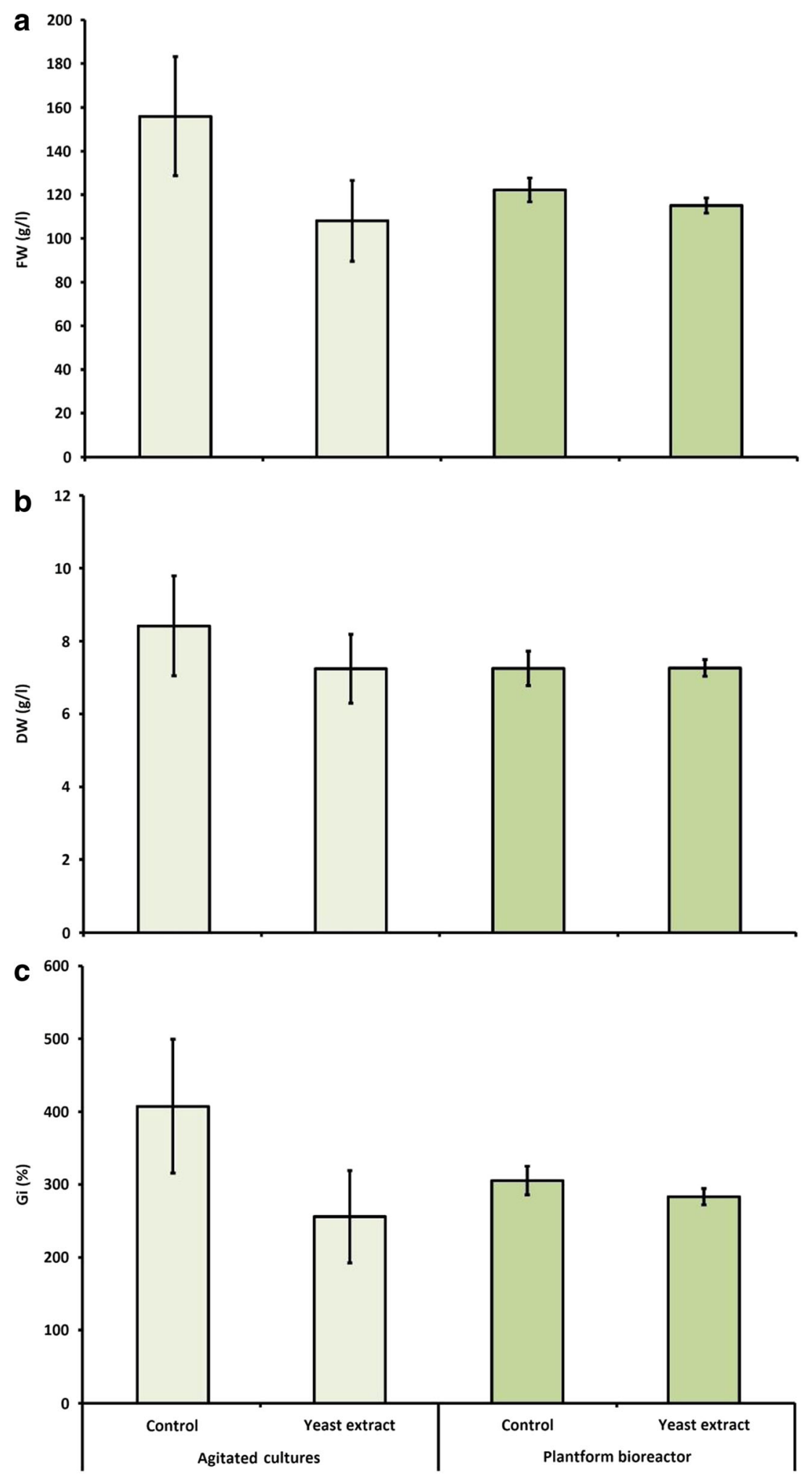

elicitation procedures did not affect the qualitative composition of the lignan set present in S. chinensis microshoots. Irrespectively of the applied elicitation strategy, only the traces of the studied lignans were detected in the experimental media samples.
The conducted experiments confirm that elicitation with $\mathrm{CdCl}_{2}$ is an effective means of improving dibenzocyclooctadiene lignan production in $S$. chinensis cultures. The results also show that $\mathrm{CdCl}_{2}$ concentration can be reduced up to 20 times while retaining the elicitor's efficacy (Table 1 and Table S3). So far, 
Fig. 5 Comparison of reached maximal total contents $[\mathrm{mg} / 100 \mathrm{~g}$ $\mathrm{DW} \pm \mathrm{SD}$ ] of dibenzocyclooctadine lignans in agitated and bioreactor microshoot cultures of S. chinensis, obtained after optimization of the elicitation process, with their contents in reference plant material-leaves and fruits of soil-grown plant (Szopa et al. 2016b)

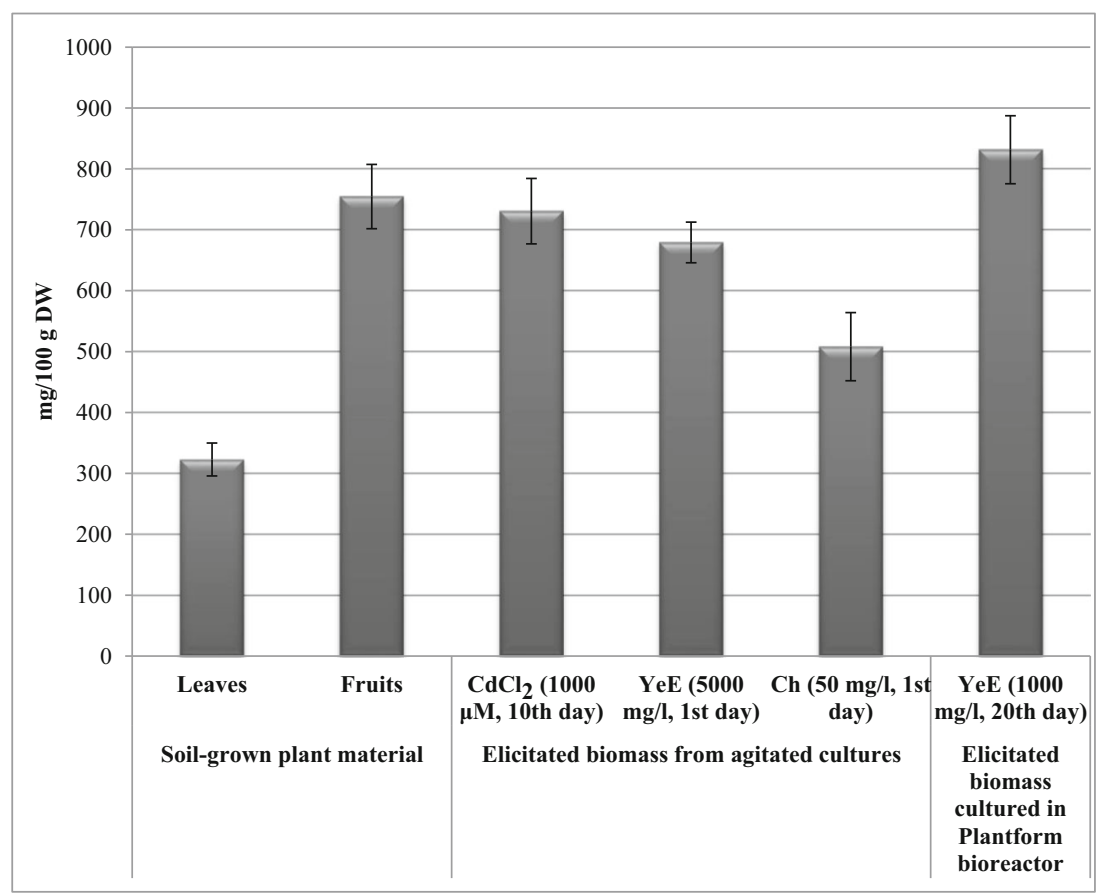

there have been relatively few reports on the effects of cadmium ions on the plant secondary metabolism. Besides boosting lignan accumulation in Phyllanthus amarus (Rai et al. 2005), they also proved to be effective (best results at $2.0 \mathrm{mM}$ ) at stimulating the biosynthesis of gymnemic acid (saponin) accumulation in Gymnema sylvestre suspension cultures (Ch and Rao 2012), tanshinone - diterpene (best results at $25 \mu \mathrm{M}$ ) in suspension cultures of Salvia miltiorrhiza (Zhao et al. 2010), and anthracene derivatives (at $10 \mu \mathrm{M}$ ) in the suspension culture of Rheum palmatum (Kasparová and Siatka 2004). The results of the abovementioned studies, as well as the present work, indicate that $\mathrm{CdCl}_{2}$ seems to be effective as an elicitor in a wide concentration range. However, its use should be limited due to an environmental burden as well as the need to remove cadmium ion residuals from the harvested biomass.

Given the toxicity of cadmium salts, the efforts were made to replace $\mathrm{CdCl}_{2}$ with safer elicitors. In the current work, the effects of two biotic elicitors (Ch and YeE) on the production of Schisandra lignans have been examined for the first time.

The most plausible results were obtained for the elicitation conducted on the 20th day of experiment. Interestingly, the selected YeE (yeast extract) elicitation schemes noticeably increased the accumulation of gomisin A (Table 2) whose concentrations exceeded schisandrin content (major lignan content in majority of the samples). At $1000 \mathrm{mg} / \mathrm{l}$ added on the 20th day, YeE stimulated the accumulation of lignans while not negatively affecting biomass growth. Therefore, the abovementioned elicitation protocol was applied for bioreactor-grown $S$. chinensis microshoots.
YeE and $\mathrm{Ch}$ are known as effective and relatively cheap elicitors, commonly employed for enhancing secondary metabolism in plant in vitro cultures (Ramirez-Estrada et al. 2016). For instance, YeE stimulated the accumulation of andrographolide - specific diterpene lactone — responsible for pharmacological action of Andrographis paniculata, in suspension cultures of the aforementioned plant species (8.8fold increase as compared with untreated cells) (Gandi et al. 2012). More importantly, in several studies, YeE has been demonstrated to be the most effective agent that increased lignan accumulation. For example, YeE considerably increased the production of lariciresinol-type lignanleolignin - in the 'hairy root' cultures of Leontopodium nivale ssp. alpinum, providing the amounts of lignans comparable to those found in roots of the parent plants (Wawrosch et al. 2014). At $1000 \mathrm{mg} / \mathrm{l}$, YeE was also reported to boost the biosynthesis of the specific neolignans-8, $4^{\prime}$ oxynorneolignans - in Echinacea purpurea cell cultures (Li and Barz 2005). Moreover, it the efficacy of YeE at stimulating the production of flavonolignans (including silychristin, silydianin, silybin, and isosilybin) was demonstrated in cell suspension cultures of Silybum marianum (Firouzi et al. 2013).

Among the elicitors employed in the present study, the second biotic elicitor, chitosan $(\mathrm{Ch})$, proved to be the least effective at improving lignan accumulation. This result is in agreement with the previous reports. For instance, $\mathrm{Ch}$ proved to be one of the less effective elicitors applied in order to enhance the accumulation of podophyllotoxin and the related lignan constituents in Linum album cell suspension cultures (Bahabadi et al. 2011). 
Ch was found to be a good elicitor in the experiment with Withania somnifera (Sivanandhan et al. 2014) suspension cultures. Ch was selected as the most favoring for the accumulation of withanolides in the agitated flasks, as well as in the bioreactor cultures; the amounts were 2.1 and 1.7 times higher than in the unelicited biomass extracts.

On the basis of our previous experiments, on the influence of different types of bioreactors on the growth parameters, and production of lignans in S. chinensis microshoots (Szopa et al. 2017b), we selected the Plantform temporary immersion system, which provided the highest lignan content, as the most favorable one, for the current work. As demonstrated in the previous reports (Pérez-Alonso et al. 2009; Georgiev et al. 2014; Ptak et al. 2017), the temporary immersion systems are also suitable for the elicitation experiments.

The results obtained from the bioreactor experiment offer the possibility to advance the production of Schisandra lignans, based on increasing their content in view of an elicitation method. Correspondingly, there are the attempts to boost the production of taxuyunnanine $\mathrm{C}$, the taxane precursor, which is the plant metabolite of the great anticancer value, in suspension cultures of Taxus chinensis by maintaining the culture in airlift bioreactor, elicited with MeJa (Dong and Zhong 2002). Promising, though, are also the results in increasing ginsenoside production, a metabolite of an outstanding biological activity, which were established after MeJa elicitation of cell suspension cultures of Panax ginseng, in 5-liter balloon-type bubble bioreactors (Thanh et al. 2005).

The elicitation experiments on $S$. chinensis microshoots provided promising results in terms of improving dibenzocyclooctadiene lignan accumulation. The maximal total contents of Schisandra lignans, estimated in the elicited cultures, were higher than in the leaves of the parent plant and comparable (or even higher) to the pharmacopoeial plant raw material—Schisandra fruits (Fig. 5). The highest amount of the lignans produced by the biomass elicited with $1000 \mathrm{mg} / \mathrm{l} \mathrm{YeE}$ on the 20th day in Plantform bioreactor was $10 \%$ higher than in fruits and 39\% higher than in the leaves of the parent plant (Fig. 5) (Szopa et al. 2016b). The successful transfer of the elicitation experiment from the agitated cultures to the bioreactor scale offers the possibility to advance the production of Schisandra lignans and creates prospects for practical applications of the presented results.

Funding This study was funded by National Science Centre, Poland (grant number 2016/23/D/NZ7/01316).

\section{Compliance with ethical standards}

Conflict of interest The authors declare that they have no conflict of interest.

Ethical approval This article does not contain any studies with human participants or animals performed by any of the authors
Open Access This article is distributed under the terms of the Creative Commons Attribution 4.0 International License (http:// creativecommons.org/licenses/by/4.0/), which permits unrestricted use, distribution, and reproduction in any medium, provided you give appropriate credit to the original author(s) and the source, provide a link to the Creative Commons license, and indicate if changes were made.

\section{References}

Angelova Z, Georgiev S, Roos W (2006) Elicitation of plants. Biotechnol Biotechnol Equip 20(2):72-83. https://doi.org/10.1080/13102818. 2006.10817345

Arroo RRJ, Alfermann AW, Medarde M, Petersen M, Pras N, Woolley JG (2002) Plant cell factories as a source for anti-cancer lignans. Phytochem Rev 1(1):27-35. https://doi.org/10.1023/A: 1015824000904

Bahabadi ES, Sharifi M, Safaie N, Murata J, Yamagaki T, Satake H (2011) Increased lignan biosynthesis in the suspension cultures of Linum album by fungal extracts. Plant Biotechnol Rep 5(4):367373. https://doi.org/10.1007/s11816-011-0190-3

Bhattacharyya D, Sinha R, Ghanta S, Chakraborty A, Hazra S (2012) Proteins differentially expressed in elicited cell suspension culture of Podophyllum hexandrum with enhanced podophyllotoxin content. Proteome Sci 10:34-34. https://doi.org/10.1186/1477-5956$10-34$

Capote A (2012) Increased cardenolides production by elicitation of Digitalis lanata shoots cultured in temporary immersion systems. Plant Cell Tissue Organ Cult 110(1):153-162. https://doi.org/10. 1007/s11240-012-0139-4

Ch B, Rao K (2012) Abiotic elicitation of gymnemic acid in the suspension cultures of Gymnema sylvestre. World J Microbiol Biotechnol 28(2):741-747. https://doi.org/10.1007/s11274-011-0870-8

Dong H-D, Zhong J-J (2002) Enhanced taxane productivity in bioreactor cultivation of Taxus chinensis cells by combining elicitation, sucrose feeding and ethylene incorporation. Enzym Microb Technol 31(12):116-121. https://doi.org/10.1016/S0141-0229(02)00079-0

Esmaeilzadeh Bahabadi S, Sharifi M, Murata J, Satake H (2014) The effect of chitosan and chitin oligomers on gene expression and lignans production in Linum album cell cultures. J Med. Plants 1: 46-53

European Directorate for the Quality of Medicines. (2017) Schisandrae chinensis fructus. In: European Pharmacopoeia 9.0. Strasburg,

Firouzi A, Mohammadi SA, Khosrowchahli M, Movafeghi A, Hasanloo T (2013) Enhancement of silymarin production in cell culture of Silybum marianum (L) Gaertn by elicitation and precursor feeding. J Herbs Spices Med Plants 19(3):262-274. https://doi.org/10.1080/ 10496475.2013.791908

Fuss E (2004) Lignans in plant cell and organ cultures: an overview. Phytochem Rev 2:307-320

Gandi S, Rao K, Chodisetti B, Giri A (2012) Elicitation of andrographolide in the suspension cultures of Andrographis paniculata. Appl Biochem Biotechnol 168(7):1729-1738. https:// doi.org/10.1007/s12010-012-9892-4

Georgiev V, Schumann A, Pavlov A, Bley T (2014) Temporary immersion systems in plant biotechnology. Eng Life Sci 14(6):607-621. https://doi.org/10.1002/elsc.201300166

Jaremicz Z, Luczkiewicz M, Kokotkiewicz A, Krolicka A, Sowinski P (2014) Production of tropane alkaloids in Hyoscyamus niger (black henbane) hairy roots grown in bubble-column and spray bioreactors. Biotechnol Lett 36(4):843-853. https://doi.org/10.1007/s10529013-1426-9 
Kasparová M, Siatka T (2004) Abiotic elicitation of the explant culture of Rheum palmatum L. by heavy metals. Ceska Slov Farm 53(5):252255

Koulman A, Beekman AC, Pras N, Quax WJ (2003) The bioconversion process of deoxypodophyllotoxin with Linum flavum cell cultures. Planta Med 69(8):739-744. https://doi.org/10.1055/s-2003-42785

Li W-W, Barz W (2005) Biotechnological production of two new 8,4' oxynorneolignans by elicitation of Echinacea purpurea cell cultures. Tetrahedron Lett 46(17):2973-2977. https://doi.org/10.1016/ j.tetlet.2005.03.036

Lu Y, Chen D-F (2009) Analysis of Schisandra chinensis and Schisandra sphenanthera. J Chromatogr A 1216(11):1980-1990. https://doi. org/10.1016/j.chroma.2008.09.070

Luczkiewicz M, Kokotkiewicz A (2012) Elicitation and permeabilisation affect the accumulation and storage profile of phytoestrogens in high productive suspension cultures of Genista tinctoria. Acta Physiol Plant 34(1):1-16. https://doi.org/10.1007/s11738-011-0799-4

Malik S, Bíba O, Grúz J, Arroo RRJ, Strnad M (2014) Biotechnological approaches for producing aryltetralin lignans from Linum species. Phytochem Rev 13(4):893-913. https://doi.org/10.1007/s11101014-9345-5

Mannan A, Liu C, Arsenault PR, Towler MJ, Vail DR, Lorence A, Weathers PJ (2010) DMSO triggers the generation of ROS leading to an increase in artemisinin and dihydroartemisinic acid in Artemisia апnиa shoot cultures. Plant Cell Rep 29(2):143-152. https://doi.org/10.1007/s00299-009-0807-y

Mocan A, Zengin G, Crișan G, Mollica A (2016) Enzymatic assays and molecular modeling studies of Schisandra chinensis lignans and phenolics from fruit and leaf extracts. J Enzyme Inhib Med Chem 6366(sup4):1-11. https://doi.org/10.1080/14756366.2016.1222585

Murashige T, Skoog F (1962) A revised medium for rapid growth and bioassays with tobacco tissue cultures. Physiol Plant 15(3):473-479. https://doi.org/10.1111/j.1399-3054.1962.tb08052.x

Opletal L, Sovová H, Bártlová M (2004) Dibenzo[a,c]cyclooctadiene lignans of the genus Schisandra: importance, isolation and determination. J Chromatogr B 812(1-2):357-371. https://doi.org/10.1016/ j.jchromb.2004.07.040

Panossian A, Wikman G (2008) Pharmacology of Schisandra chinensis Bail.: an overview of Russian research and uses in medicine. $\mathrm{J}$ Ethnopharmacol 118(2):183-212. https://doi.org/10.1016/j.jep. 2008.04.020

Pérez-Alonso N, Wilken D, Gerth A, Jähn A, Nitzsche H-M, Kerns G, Capote-Perez A, Jiménez E (2009) Cardiotonic glycosides from biomass of Digitalis purpurea L. cultured in temporary immersion systems. Plant Cell Tissue Organ Cult 99(2):151-156. https://doi. org/10.1007/s11240-009-9587-x

Petersen MM, Alfermann W (2001) The production of cytotoxic lignans by plant cell cultures. Appl Microbiol Biotechnol 55(2):135-142. https://doi.org/10.1007/s002530000510

Ptak A, Morańska E, Saliba S, Zieliński A, Simlat M, Laurain-Mattar D (2017) Elicitation of galanthamine and lycorine biosynthesis by Leucojum aestivum L. and L. aestivum "Gravety Giant" plants cultured in bioreactor RITA®. Plant Cell Tissue Organ Cult 128(2): 335-345. https://doi.org/10.1007/s11240-016-1113-3

Rai V, Khatoon S, Bisht SS, Mehrotra S (2005) Effect of cadmium on growth, ultramorphology of leaf and secondary metabolites of Phyllanthus amarus Schum. and Thonn. Chemosphere 61(11): 1644-1650. https://doi.org/10.1016/j.chemosphere.2005.04.052
Ramirez-Estrada K, Vidal-Limon H, Hidalgo D, Moyano E, Golenioswki M, Cusidó RM, Palazon J (2016) Elicitation, an effective strategy for the biotechnological production of bioactive high-added value compounds in plant cell factories. Molecules 21(2):182-182. https:// doi.org/10.3390/molecules21020182

Shi P, He Q, Zhang Y, Qu H, Cheng Y (2009) Characterisation and identification of isomeric dibenzocyclooctadiene lignans from Schisandra chinensis by high-performance liquid chromatography combined with electrospray ionisation tandem mass spectrometry. Phytochem Anal 20(3):197-206. https://doi.org/10.1002/pca.1115

Sivanandhan G, Selvaraj N, Ganapathi A, Manickavasagam M (2014) Enhanced biosynthesis of withanolides by elicitation and precursor feeding in cell suspension culture of Withania somnifera (L.) dunal in shake-flask culture and bioreactor. PLoS One 9(8):1-9. https:// doi.org/10.1371/journal.pone.0104005

Szopa A, Klimek M, Ekiert H (2016a) Chinese magnolia vine (Schisandra chinensis) - therapeutic and cosmetic importance (Cytryniec chiński (Schisandra chinensis) —znaczenie lecznicze i kosmetyczne). Pol J Cosmetol 19:274-284

Szopa A, Kokotkiewicz A, Marzec-Wróblewska U, Bucinski A, Luczkiewicz M, Ekiert H (2016b) Accumulation of dibenzocyclooctadiene lignans in agar cultures and in stationary and agitated liquid cultures of Schisandra chinensis (Turcz.) Baill. Appl Microbiol Biotechnol 100(9):3965-3977. https://doi.org/10.1007/s00253-015-7230-9

Szopa A, Ekiert R, Ekiert H (2017a) Current knowledge of Schisandra chinensis (Turcz.) Baill. (Chinese magnolia vine) as a medicinal plant species: a review on the bioactive components, pharmacological properties, analytical and biotechnological studies. Phytochem Rev 16(2):195-218. https://doi.org/10.1007/s11101-016-9470-4

Szopa A, Kokotkiewicz A, Łuczkiewicz M, Ekiert H (2017b) Schisandra lignans production regulated by different bioreactor type. J Biotechnol 247:11-17. https://doi.org/10.1016/j.jbiotec.2017.02. 007

Thanh NT, Murthy HN, KW Y, Hahn EJ, Paek KY (2005) Methyl jasmonate elicitation enhanced synthesis of ginsenoside by cell suspension cultures of Panax ginseng in 5-1 balloon type bubble bioreactors. Appl Microbiol Biotechnol 67(2):197-201. https://doi.org/ 10.1007/s00253-004-1759-3

Verpoorte R, Contin A, Memelink J (2002) Biotechnology for the production of plant secondary metabolites. Phytochem Rev 1(1):13-25. https://doi.org/10.1023/A:1015871916833

Wawrosch C, Schwaiger S, Stuppner H, Kopp B (2014) Lignan formation in hairy root cultures of Edelweiss (Leontopodium nivale ssp. alpinum (Cass.) Greuter). Fitoterapia 97:219-223. https://doi.org/ 10.1016/j.fitote.2014.06.008

World Health Organization (2007) WHO monographs on selected medicinal plants, vol 3. Fructus Schisandrae, Geneva

Zhang H, Zhang G, Zhu Z, Zhao L, Fei Y, Jing J, Chai Y (2009) Determination of six lignans in Schisandra chinensis (Turcz.) Baill. fruits and related Chinese multiherb remedies by HPLC. Food Chem 115(2):735-739. https://doi.org/10.1016/j.foodchem. 2008.12.010

Zhao J, Zhou L, Wu J (2010) Effects of biotic and abiotic elicitors on cell growth and tanshinone accumulation in Salvia miltiorrhiza cell cultures. Appl Microbiol Biotechnol 87(1):137-144. https://doi.org/10. 1007/s00253-010-2443-4 